\title{
Research on Problems and Countermeasures of Students' Mental Health Education in Higher Vocational Colleges
}

\author{
Xin Zeng \\ Sichuan Vocational and Technical College \\ Suining, Sichuan, 629000, China
}

\begin{abstract}
In recent years, the physical and mental health of higher vocational students has been influenced by diversified values and bad information. How to effectively grasp the unique and complex psychological characteristics of vocational students and strengthen and improve the mental health education of vocational students will have a crucial impact on the career development of higher vocational students. By summarizing the mental health status and the existence questions of higher vocational college students, this paper explores strategies to solve the mental health problems of current vocational students, thus providing a reference for improving the mental health of vocational students and effectively assisting the comprehensive development of moral, intellectual, and physical education of vocational students.
\end{abstract}

Keywords-Higher vocational colleges, Mental health education, Countermeasures

\section{INTRODUCTION}

At present, China is in a period of rapid development of science and technology. The economic, social and other levels have also become more market-oriented and diversified with the progress of the times. The complex social ecology has stricter requirements on the quality of talents; higher vocational students are faced with multiple pressures from learning, professional literacy, life goals and employments. Faced with these pressures, some high-level students have psychological problems such as anxiety, inferiority, depression, etc., which not only directly affects university study and life, but also affects the development of the will, personality, temperament, and even the shaping of a healthy personality. Therefore, strengthening and improving the mental health education of vocational students have important practical significance for improving the physical and mental health of higher vocational students, and have a positive role in comprehensively implementing the party's educational policy and improving the ideological and political education in colleges and universities.

\section{STATUS QUO AND PROBLEMS OF MENTAL HEALTH} EDUCATION FOR STUDENTS IN HIGHER VOCATIONAL COLLEGES

At present, all higher vocational colleges attach great importance to the management of mental health education for higher vocational students. A series of measures have been taken to strengthen the management of mental health education for vocational students. For example, at the beginning of the school, all the freshmen will be psychologically surveyed, the problem students will be investigated, and the psychological growth tracking files of the problem students will be established. The psychological health education related courses will be offered to improve the psychological quality of the higher vocational students and cultivate them to establish a correct world view and values form a positive outlook on life. They establish a psychological health counseling center to provide psychological counseling services, carry out online and offline mental health knowledge publicity, mental health education series activities. Gradually, it realized the transformation of mental health education for vocational students from point to point, from mandatory to voluntary. The mental health education of students in higher vocational colleges has achieved phased results. However, in the daily student education management, we still encounter some problems caused by students' poor academic performance, weak learning ability and poor quality of life due to mental health problems. Some students have dropped out of school due to mental health problems, and even because of psychology. The problem caused some extreme events to occur, in response to such a situation, in-depth analysis of the reasons for the poor mental health status of these students, including social, vocational schools, individual students, families and other aspects have an impact on the mental health of higher vocational students.

\section{A. Social level: lack of good social and psychological environment}

The social psychological environment refers to the reflection of the living environment of the human brain on the factors of productivity, production relations and social ideology in social life, and the social psychological atmosphere formed on this basis [1]. Since the media era, higher vocational students have often received unscrupulous or even counterfeit social phenomena, such as civic morality decline, negative values, and behavioral imbalances. Such negative information and behaviors have a negative impact on the psychology of higher vocational students who lack cognitive ability, lack of rational thinking and discernment. However, in the process of mental health education for higher vocational students, the social level often overlooks the subtle influence of the social psychological environment in the psychological development of higher vocational students, and has not taken corresponding 
measures to correct social cognitive bias. To create a good social and psychological environment for the construction of health psychology of vocational students, it is difficult to effectively prevent some adverse phenomena that have a negative impact on the psychology of higher vocational students.

\section{B. School level: mental health education needs to be improved}

1) Insufficient attention to the deep-seated problems of higher vocational students

At present, the emphasis on the mental health education of college students in various higher vocational colleges has been significantly improved, through the individual and group counseling for students, the establishment of psychological counseling centers, and the organization of mental health special activities and other measures to strengthen the mental health education for higher vocational students, in order to solve the problem of mental health education in higher vocational students. However, the attention to the deep-rooted causes of psychological problems of vocational students is not enough. The cognitive self and social, interpersonal communication and communication needs that are common in the student population are not fully recognized, and some vulnerable students have their own unique psychological needs. There are certain lags in mental health work measures.

\section{2) Mental health education professional team is} insufficient

Strengthening the construction of the teaching staff is the key to doing a good job in mental health education. The development of education ultimately depends on the level and quality of the teaching staff. The development of the level of mental health education in schools depends on the level and development of teachers engaged in mental health education [2]. At present, teachers engaged in mental health education in higher vocational colleges are mainly composed of full-time psychological teachers in psychology and education, part-time teachers in other disciplines with psychological background, and ideological and political workers and full-time counselors engaged in student education management. Since the Ministry of Education expressly stipulates that full-time teachers of mental health education in colleges and universities must have relevant academic qualifications and professional qualifications for college students' mental health education, the proportion of full-time teachers in higher vocational colleges is very low. Most part-time teaching teachers have limited professional level. Indoctrinating teaching to complete teaching tasks, lack of individual communication and interaction with students, but also can't effectively solve the mental health problems of higher vocational students, the mental health of higher vocational students can’t be improved.

\section{3) Mental health education mechanism is not smooth}

Mental health education is closely related to the development of all aspects of higher vocational students. It has its relative independence and requires good cooperation between various departments to jointly carry out and promote work. If you only rely on a specialized mental health education institution to carry out this work, you can't fully play the role of mental health education. At present, there is not coordinated and unified deployment among various departments, and it is impossible to effectively carry out the mental health education work of vocational students, and it is difficult to fully mobilize the educational power of all aspects [3]. Moreover, in the comprehensive development of mental health education, all higher vocational colleges lack a professional evaluation department for mental health. The evaluation process is too simplistic and one-sided, and it is not able to solve the assessment problem well and ensure the actual effect of mental health education.

\section{Family level: failure to fully understand the psychological needs of children}

In addition to the constraints of social and school factors, the family factors have also played a vital role in the healthy growth of physical education. In real life, due to the busy work of parents and their children studying abroad, some families have gradually reduced the relationship between parents and their children, and have not established effective communication channels with schools, which has finally formed a vacuum zone for family education. In addition, some families have done too much protection and care for their children, and they have arranged everything for their children according to their own ideas. They have not fully understood the psychological needs of their children in an "equality dialogue" and guided their children to solve the psychological problems. In addition, some parents are limited by their own level of knowledge. When their children have psychological problems, they cannot be treated correctly. The reasons are attributed to the temperament and contrived, and they can't give the children the right help.

\section{Student level: lack of correct self-awareness, health awareness}

Entering higher vocational colleges, Students' living environment and learning environment have huge changes. They have to face all kinds of pressure, study pressure, life pressure, and interpersonal pressure[4]. Some higher vocational students have their own self-awareness, subjective self and objective self, ideal self and real self because of their high ideals, their lack of correct grasp of society, and their lack of comprehensive and correct understanding. Contradictions, coupled with their own poor psychological adjustment, lead to temporary or long-term anxiety and confusion. When these problems occur, they fail to recognize the importance of mental health in a timely and correct manner. They are worried about being discussed and ridiculed by others. They can only choose to bear it alone, which increases psychological pressure and leads to the emergence of psychological problems.

\section{STRATEGIES FOR DEVELOPING STUDENTS' MENTAL HEALTH EDUCATION IN HIGHER VOCATIONAL COLLEGES}

\section{A. Build a good social environment and help mental health education}

The environment is an important factor affecting human development. The social environment plays an important role in the formation and development of the psychological status of 
vocational students. The breath and transformation of social life are directly related to the growth of higher vocational students. Therefore, the social public application is advancing with the times to actively participate in the construction of a good social psychological environment, actively disseminate positive energy, so that higher vocational students feel the hard work, health, optimism and tenacity from life. People and things, lead the high vocational students with the example of demonstration power. At the same time, the public should correctly understand mental health issues, and take into account the shortcomings and deficiencies of higher vocational students in an inclusive manner. Providing ways for them to release and eliminate inner oppression and confusion reasonably, and promoting the effective combination of students' self-protection and external protection, so as to provide help for the growth of vocational students.

\section{B. Promote curriculum construction and reform, and strengthen the professional construction of the teaching staff}

To carry out mental health education, teachers are a mandatory condition and curriculum is the main way. Therefore, vocational colleges should strive to build solid teachers for mental health education and strengthen the construction of mental health education curriculum [5]. On the one hand, it should be guided by the actual needs of students, from the traditional "teacher-centered" teaching mode to the "student-centered", adhere to the active and experiential teaching principles, and the "indoctrination" teaching and " "Formative" teaching combines thematic and case teaching with the theme of mental health, highlights the subjectivity of students, enhances students' practical experience, and guides students to share, feel and grow in participation. On the other hand, it should be based on professional theory, knowledge, practical ability, professional ethics and other aspects will increase the training of mental health education team, so that the team engaged in higher vocational mental health education not only masters the professional knowledge of psychology, but also applies the theoretical knowledge to practice. Among them, they gradually build a team of mental health education in higher vocational colleges with comprehensive ability, so as to adapt to and meet the needs of the rapid development of higher vocational education and the training of higher vocational talents.

\section{Give full play to the role of the family and realize the "co- education of home and school"}

Family is the first school in the process of student growth, so family education is very important for students' mental health[6]. A good family environment has a positive role in regulating students' behavior habits and developing good ideology and morality. After entering the university, the vocational students begin to live away from the family, independent and independent life, in the face of various problems and difficulties that they have never encountered before. And lacking of parental companionship and communication, they are bound to feel unfit. There are even some psychological obstacles. Therefore, higher vocational colleges should strengthen communication with parents of students, guide parents to focus on and improve their behavior, correctly handle the relationship between family members, and strive to build a harmonious and relaxed learning and living environment for students. The behavior helps and guides students to discover their own problems and prevent their psychological problems.

\section{Establish a correct self-awareness and enhance the awareness of maintaining mental health}

Entering higher vocational colleges means that students have entered an important period of independent personality formation. They have just made the transition from high school to college, and then they will soon face the unknown challenge of becoming a "social person". In such a special stage, it is often easier to appear psychological discomfort and affect mental health with the change of external environment and individual physical and mental factors. Therefore, in the process of mental health education, higher vocational students should continuously sum up experience in participating in theoretical studies and social activities, improve their cognitive abilities, establish correct self-awareness, understand self, grasp self, and actively participate in various mental health education activities, learn to maintain your own mental health, take the initiative to exert the positive initiative of selfawareness, overcome the negative effects of negative psychology, and strive to continuously transform and improve, thus gain promotion and development.

\section{CONCLUSION}

Mental health education for vocational students is a complex and important task. It is necessary to fully mobilize the power of society, colleges, parents and students to work together to optimize and promote this work. This paper starts from the current situation and existing problems of students' mental health education in contemporary higher vocational colleges. The current status and problems of mental health education will be faced by constructing a good social environment, promoting curriculum construction and reform, strengthening the professionalization of the teaching staff, depending on the family role, and establishing correct selfconsciousness. It can improve the psychological resources of higher vocational students, fundamentally prevent and control mental health problems, and ensure that higher vocational students gain their own transcendence and growth.

\section{ACKNOWLEDGMENT}

This paper is the research result of "Optimization of Moral Education Work in Higher Vocational Colleges" (Project No.: CJF16038).

\section{REFERENCE}

[1] Tang Yaoyang, Thoughts on College Students' Mental Health Education, Hefei University of Technology, 2009.

[2] Zhang Xiao, Liu Shijun, The Status Quo of Contemporary College Students' Mental Health Education, Sports Vision, pp. 250-251, 2018. 
[3] Fan Linlin, Research on the Mental Health Education of College Students in China, Party School of Shandong Provincial Party Committee, 2016.

[4] Shen Chunjing, Research on the status quo and countermeasures of mental health education for $\mathrm{Z}$ vocational students, Hebei Normal University, 2018.
[5] Dong Yinghui, Research on psychological health status and educational countermeasures of vocational college students in Qinhuangdao [D], Hebei Normal University of Science and Technology, 2015.

[6] Chen Jingtian, Research on College Students' Mental Health Education from the Perspective of Psychological Flexibility, Modern Vocational Education, pp. 232-233, 2019. 